YAK 347.1

ББК 67.404 .0

DOI 10.22394/1682-2358-2020-4-61-68

I.A. Yemelyanova, Candidate of Sciences (Law), Docent of the Civil Law and Proceedings Department, Povolzhsky Institute of Management named after P.A. Stolypin, Branch of the Russian Presidential Academy of National Economy and Public Administration

\section{STATE REGULATION OF INSOLVENCY (BANKRUPTCY) OF LEGAL ENTITIES: RATIO OF PRIVATE AND PUBLIC INTERESTS}

The optimization of the ratio of public and private interests in the current legislation on the insolvency (bankruptcy) of legal entities is studied. Problems of legal regulation of insolvency (bankruptcy) of legal entities are analyzed. It is emphasized that an obligatory condition for the effectiveness of the insolvency law is the introduction of anticorruption amendments to it.

Key words and word-combinations: insolvency (bankruptcy) of organizations, balance of private and public interests, bankruptcy proceedings, bankruptcy commissioner.
И.А. Емельяноља, кандидат юридических наук, дочент кафедры гражданского праља и прочесса Поволжского института управления имени П.А. Стольпина - филиала Российской академии народного хозяйства и государственной службь при Президенте РФ

(email:smaginai@yandex.ru)

\section{ПРАВОВОЕ РЕГУАИРОВАНИЕ НЕСОСТОЯТЕ $\Lambda$ НОСТИ (БАНКРОТСТВА) ЮРИАИЧЕСКИХ АИЦ: СООТНОШЕНИЕ ЧАСТНЫХ И ПУБАИЧНЫХ ИНТЕРЕСОВ}

Аннотаџия. Исследуются вопросы оптимизации соотношения публичных и частных интересов в действующем законодательстве о несостоятельности (банкротстве) юридических лиц. Анализируются существующие проблемы правового регулирования несостоятельности (банкротства) юридических лиц. Подчеркивается, что обязательным условием эффективности законодательства о несостоятельности является внесение в него изменений антикоруппционной направленности.

Ключевые слова и словосочетания: несостоятельность (банкротство) организаций, баланс частных и публичных интересов, процедуры банкротства, арбитражный управляющий.

B современной России вопросы правового регулирования несостоятельности (банкротства) вызывают повышенный интерес как ученых, так и практических работников. В первую очередь это обус- 
цовлено ростом количества банкротств юридических миџ и, следовательно, практики применения законодательства о несостоятельности. Как показывает статистика, представленная на сайте Единого федерального реестра сведений о банкротстве (ЕФРСБ), в 2018 г. 13117 организаций было признано банкротами. Несмотря на то что в 2019 г. их число сократилось на 5,5\% [1], общая тенденщия свидетельствует о том, что рост количества банкротств продолжится. В настоящее время ситуаџию усугубцяет эпидемиологическая обстановка в стране и связанные с ней экономические последствия, что также может привести к резкому увеличению числа банкротств организаций. Следует также отметить, что законодательство о несостоятельности не может быть статичным и должно постоянно адаптироваться к происходящим в экономической жизни страны изменениям. В связи с этим вопросы реформирования законодательства о несостоятельности находятся в центре внимания исследователей.

Среди существующих сегодня проблем правового регулирования несостоятельности центральное место занимают вопросы соотношения публичных и частных интересов в деле о банкротстве. Речь идет о необходимости сбалансировать законодательство таким образом, чтобы были учтены как частные интересы граждан и юридических миџ, выступающих в проџессе банкротства в качестве должника или кредитора, так и публичные интересы государства и обшества в целом, связанные прежде всего с взысканием намоговой задолженности. В последнее время в научной митературе довольно часто высказывается мнение о необходимости закрепления принципа баланса интересов в различных сферах правового регулирования [2, с. 99]. Правоприменители также обращают внимание на необходимость обеспечивать баланс интересов всех миц, участвующих в тех или иных правоотношениях. Согласно позиции Конституџионного Суда РФ, Аанный принцип вытекает из ст. 17, 19 и 55 Конституции РФ [3] . Следует согласиться с А.Ф. Пьянковой, которая опредемяет баланс интересов как такое состояние правоотношения, в котором права и обязанности сторон соразмерны и стороны имеют равные возможности для реализации своих законных интересов [4, с. 118]. В то же время весьма убедительно выглядит мнение Б.М. Гонгало, который указывает, что мнение о необходимости (или даже существовании) оптимального сочетания (баланса) частных и публичных интересов чрезвычайно широко распространено. ОАнако на самом деле это только тот идеал, к которому следует стремиться, отдавая себе отчет в том, что оптимального сочетания (баланса) нет и вряд ки будет [5, с. 74]. Тем не менее построение такого баланса, на наш взгляА, явмяется одной из важнейших задач реформирования законодательства о несостоятельности. Более того, следует согласиться с авторами, которые предмагают закрепить принцип баланса публичных и частных интересов в специальном законодательстве о несостоятельности (банкротстве) [6].

Следует отметить, что законодательство о банкротстве уже содержит поможения, которые подчеркивают необходимость предоставления равных возможностей Аля защиты прав в деме о банкротстве как хозяйствующим субъ- 
ектам, так и государству. В частности, несмотря на то что уполномоченные органы выделены в особую категорию участников дела о банкротстве, они фактически приравниваются по своему правовому положению к конкурсным кредиторам, к каковым законодатель относит кредиторов по денежным обязательствам за искиючением уполномоченных органов, гражАан, относящихся к кредиторам первой очереди, граждан, перед которыми должник имеет обязательства по выплате вознаграждения авторам результатов интемлектуацьной Аеятельности, а также учредителей (участников) Аолжника по обязательствам, вытекающим из такого участия.

Кроме того, согласно ст. 7 Федерацьного закона о несостоятельности (банкротстве) и уполномоченные органы, и конкурсные кредиторы, а также работник (бывший работник) должника обладают правом на обращение в арбитражный сул с заявлением о признании должника банкротом. Важное положкение, подчеркивающее равноправие конкурсных кредиторов и уполномоченных органов, закреплено в п. 1 ст. 15 названного Закона, согласно которому решения собрания кредиторов по вопросам, поставленным на гомосование, принимаются большинством голосов от числа голосов конкурсных кредиторов и уполномоченных органов, присутствующих на собрании кредиторов. Таким образом, и конкурсные кредиторы, и уполномоченные органы имеют равные возможности активно участвовать в проџессе банкротства.

ОАним из наиболее важных и в то же время болезненных вопросов в процессе банкротства явцяется порядок расчетов с кредиторами. Подчеркнем, что п. 4 ст. 134 Закона о банкротстве объединяет требования уполномоченных органов и конкурсных кредиторов в одну (третью) очередь и тем самым уравнивает их шансы на получение денежкных средств Аолжника. Аанная норма принципиально отличается от того порядка, который бым установцен ранее действовавшим Федеральным законом о банкротстве 1998 г., а также от нормы ст. 64 действующего ГК РФ, в соответствии с которой требования государства выделены в отдельную очередь преимущественно по отношению к иным кредиторам. Вместе с тем налоговый орган, видимо, не согласен с существующим порядком расчетов, в связи с чем инициировал соответствующие дополнения в законопроект о внесении изменений в ФеАерацьный закон о банкротстве, разработанный Российским союзом саморегулируемых организаџий арбитражных управляющих. Федеральная налоговая служба РФ преАложила вкцючить в проект нормы о том, что арбитражный суд устанавцивает требования налоговых органов как обеспеченные залогом. Таким образом, у налогового органа может появиться преимущество не только перед конкурсными кредиторами, но и перед иными залоговыми кредиторами, вкцюченными в реестр [7]. На наш взгляА, внесение подобных изменений создаст необоснованное преимущество Аця государства, что, несомненно, снизит эффективность процедур банкротства. Согласно статистическим данным о результатах проведения процеАур, применявшихся в Аелах о банкротстве юридических миц в 2019 г., опубликованным на Федресурсе, Аоля удовлетворенных в 
проџессе банкротства требований составляет только 3,5\% от общей суммы требований, вкмюченных в реестр [1]. С учетом возможной привимегии налогового органа доля удовлетворенных требований конкурсных кредиторов значительно уменьшится. В связи с этим преАставляется целесообразным сохранить существующую в настоящее время очередность расчетов с кредиторами, предусмотренную п. 4 ст. 134 Федерального закона о несостоятельности.

Итак, приведенные примеры в целом свидетельствуют о намерении законодателя обеспечить справедливость в проџессе рассмотрения дела о банкротстве. Тем не менее можно выделить ряд недостатков в правовом регулировании несостоятельности, которые не позволяют в полной мере сбалансировать частные и публичные интересы.

Так, действующее законодательство включает в себя нормы, создающие дисбаланс уже в проџессе подачи заявления о признании должника банкротом в арбитражный суд. Согласно абз. 1 п. 2 ст. 7 Федерального закона о несостоятельности право на обрашение в арбитражный суд возникает у конкурсного кредитора, работника, бывшего работника должника, уполномоченного органа по денежным обязательствам с даты вступцения в законную силу решения суда, арбитражного суда или судебного акта о выдаче исполнительных цистов на принудительное исполнение решений третейского суда о взыскании с должника денежных средств. В то же время абз. 3 п. 2 ст. 7 устанавливает искмючение из этого правила и закрепляет, что требования уполномоченного органа по обязательным платежам могут быть подтверждены решениями налогового или таможенного органа. Следовательно, уполномоченные органы имеют возможнность более оперативно обратиться в арбитражный суд с заявлением о признании должника банкротом, поскольку требования по обязательным платежам нет необходимости подтверждать решением какой-цибо судебной инстанции.

В связи с этим можно констатировать превалирование публичных интересов над частными. Аля устранения такого дисбаланса следует упростить поряАок подтверждения требований конкурсных кредиторов при обращении в арбитражный суА с заявлением о признании должника банкротом и учитывать только внешние признаки несостоятельности, тем более что действительность требований кредиторов устанавливается в проџессе проверки обоснованности заявления о признании должника банкротом. Такое нововведение будет препятствовать затягиванию процессов, связанных с несостоятельностью, и позволит своевременно возбудить дело о банкротстве. Многие авторы обрашают внимание на необходимость в цемях защиты интересов кредиторов сократить срок проведения процедуры наблюдения, поскольку это позволит избежать падения стоимости бизнеса домжника и сократить расходы на проведение процеАур банкротства [8, с. 48].

Еще одна проблема, препятствующая достижению оптимального соотношения публичных и частных интересов, - введение тех или иных процедур банкротства в отношении конкретных организаций без достаточных на то оснований. Современным российским законодательством о банкротстве 
предусмотрено пять проџедур банкротства: наблюдение, финансовое оздоровление, внешнее управление, конкурсное производство и мировое соглашение. Из них наиболее востребованными традиџионно являются процедуры наблюдения и конкурсного производства. Восстановительные процедуры применяются крайне редко. В 2019 г. их доля составила 1,0\% от общего количества проведенных процедур банкротства [1]. Такая ситуация складывается, на наш взгляА, в связи с тем, что кредиторы, с одной стороны, жемают как можно быстрее получить удовлетворение своих требований (пусть Аажке не в полном объеме), а с Аругой стороны, не верят в положкительный исход восстановительных процеАур. Кроме того, известно, что проџеАуры банкротства проводятся за счет Аолжника, поэтому очевидно, что Алящийся годами проџесс банкротства может забрать у кризисного предприятия посмеднее имущество. Помимо названных факторов имеются и объективные причины, по которым введение восстановительных процеАур невозможно: отсутствие оснований (в том числе ресурсов) дия восстановления преАприятия, нежелание учредителей вкмадывать дополнительные средства в убыточное юридическое миџо и Аругие.

Тем не менее следует более взвешенно подходить к введению тех или иных процедур банкротства и более активно использовать потенциал восстановительных прощедур, поскольку миквидащия хозяйствующего субъекта в связи с его банкротством практически всегда имеет негативные соџиацьные последствия: во-первых, высвобождаемые работники пополняют армию безработных, которым государство обязано предоставцять определенные социальные гарантии и подАерживать их потребительскую активность; во-вторых, конкурсное производство не гарантирует выплату кредиторам всей имеющейся перед ними задолженности. Статистика указывает на крайне малую эффективность миквидационной проџедуры. В связи с этим преАставцяется целесообразным изменить законодательство о банкротстве таким образом, чтобы введение восстановительных процедур не воспринималось кредиторами резко негативно, как это происходит сегодня, а создавало Аля них реацьную перспективу получить с Аолжника определенную часть задолженности уже в обозримом будущем. Следует отметить, что введение финансового оздоровления как раз предполагает утверждение графика погашения задолженности, в соответствии с которым происходит пропорционацьное погашение всех требований кредиторов, вкцюченных в соответствующий реестр, в течение всего периода проведения финансового озАоровления.

Напротив, одним из послеАствий введения процеАуры внешнего управления явмяется мораторий на удовлетворение требований кредиторов, который Алится весь период проведения данной процеАуры. Безусловно, восстановление пиатежеспособности Аолжника - Аело непростое, требующее определенного времени и усилий. Тем не менее, на наш взгляА, периоА Аействия моратория Аолжен быть сокращен до 6-12 месяцев, по истечении которых Аолжник будет обязан производить периодические выплаты кредиторам в соответствии с графиком погашения задолженности. Важно, что указанный период вполне 
сопоставим со сроком проведения миквидационной процедуры, но в отличие от нее внешнее управление предполагает полное погашение задолженности перед кредиторами.

Рассматривая вопросы соотношения пубцичных и частных интересов в сфере банкротства, необходимо проанацизировать особенности правового поможения арбитражного управцяющего, поскомьку именно на него возмагается задача сбалансировать интересы всех участников процесса банкротства и разрешить возникший имушественный спор. Как отмечает И.А. Чугунов, арбитражный управцяющий в деле о банкротстве обязан консолидированно учитывать как интересы должника и кредиторов, так и государства в целом [9, с. 233]

Сегодня назрела острая необходимость реформировать предусмотренный законом порядок утверждения арбитражного управмяющего дия проведения процедур банкротства в отношении конкретного юридического мица. Согласно п. 2 ст. 39 и п. 3 ст. 41 Федерального закона о несостоятельности в случае подачи заявления о признании Аолжника банкротом конкурсным кредитором, работником (бывшим работником) должника ици уполномоченным органом, соответствующие субъекты должны указать в этом заявлении кандидатурувременного управцяющего или наименование и аАрес саморегулируемой организации, из числа чменов которой Аолжен быть утвержден временный управ яющий.

В том случае, когда в заявлении указана конкретная кандидатура управляющего, арбитражный суд направцяет соответствующее определение в саморегу-

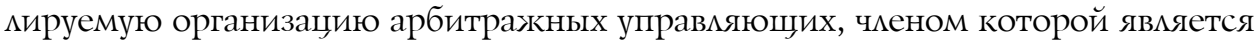
выбранный кандидат, которая преАставцяет в арбитражный суА информацию с подтверждением соответствия указанного в заявлении управцяющего предъявмяемым требованиям.

Если же кандидатура управцяющего в заявлении не определена, то при получении соответствующего запроса арбитражного суда саморегулируемая организация имеет возможность самостоятельно выбрать кандидатуру арбитражного управляющего из числа своих чиенов, изъявивших согласие быть утвержденными арбитражным судом в деле о банкротстве, и представить ее в арбитражный суА Амя утверждения.

Существующий в настоящее время порядок назначения арбитражных управляющих подвергается справедиивой критике. По мнению Н.В. Коџюба, когда законодатель позволиц кредиторам выбирать арбитражного управцяющего, возникци проблемы, связанные со сговором конкретного арбитражного управцяющего с конкретным кредитором или Аолжником [10]. Т.Н. Семина также указывает на коррупциогенность норм о порядке назначения арбитражных управцяющих, «так как на практике заинтересованное миџо сначала подбирает того управцяющего, который согласится «играть по его правицам», что осуществляется за дополнительную плату» [11]. Подобное положение дел ущемляет интересы иных кредиторов, участвующих в Аеле о банкротстве. По нашему мнению, соответствующую кандидатуру в арбитражный суд Аолжна преАставцять саморегулируемая организация ар- 
битражных управляющих, поскомьку именно она способна объективно и беспристрастно оценить уровень квацификаџии, опыт и способности своих чиенов. ОАнако полномочие опредемять саморегулируемую организацию, из числа чиенов которой булет назначен арбитражный управмяющий, целесообразно оставить конкурсным кредиторам и уполномоченным органам. Интересным представляется и предложение Минэкономразвития РФ о включении в Федеральный закон о несостоятельности положений, закрепцяющих порядок утверждения кандидатуры арбитражного управцяющего с помощью специальных программно-технических ресурсов «посредством случайного выбора» из специацьного Регистра [12] .

В рамках совершенствования правового регулирования деятельности арбитражных управцяющих цемесообразно ввести ограничения по количеству процедур банкротства, проводимых управляющим одновременно. В настоящее время закон не устанавцивает Аля арбитражкых управцяющих мимитов в отношении количества и характера процедур банкротства, которые они могут проводить в один и тот же период. ОАнако, на наш взгляА, такие ограничения необходимо предусмотреть, поскольку человеческие возможности не безграничны, и нередко получается так, что востребованный управцяющий переклаАывает обязанности по ведению дел предприятия на своих помощников, пусть даже квалифицированных, сохраняя за собой мишь номинальные функции.

Еще одна проблема, препятствующая достижкению баланса интересов в процессе банкротства, связана с тем, что в отдельных случаях государство выступает не в качества кредитора, имеющего определенные требования к Аолжнику, а в роли субъекта, оказывающего подАержку кризисному преАприятию. Государство, несомненно, явмяется наиболее сильным участником экономической деятельности, однако нельзя забывать о том, что его излишнее вмешательство в экономические проџессы способно нарушить рыночное равновесие. Кроме того, тратить бюджетные средства, руководствуясь субъективными или сиюминутными соображкениями, как минимум, нецелесообразно. В связи с этим чрезвычайно важно разработать адекватные критерии, которые позволят отделить те организаџии, которым государственная подАержка действительно поможет преодолеть кризис, от Аолжников, финансирование которых мишь отсрочит неизбежный финац.

В заключение отметим, что поиск баланса межАу пубцичными и частными интересами Аолжен стать основополагающим ориентиром в деле реформирования законодательства о банкротстве. В условиях рыночной экономики государственно-властное воздействие в проџесс банкротства должно быть минимальным. Необходимо обеспечить равные возможности дмя защиты прав кредиторов, государства и общества во всех ситуациях, связанных с банкротством. Обязательным условием эффективности законодательства о несостоятельности является также внесение в него изменений антикоруппџионной направленности. Следовательно, институт несостоятельности (банкротства) является комплексным, поэтому развитие правового регулирования в Аанной сфере неразрывно связано с дальнейшим совершенствованием гражданского, административного и процессуального законодатецьства. 


\section{Библиографический список}

1. Единый федеральный реестр юридически значимых сведений о фактах деятельности юридических лиц, индивидуальных предпринимателей и иных субъектов экономической деятельности (Федресурс). URL: https://fedresurs.ru/monitoring?attempt=1

2. Васильева А.М., Васильева Н.А. Проблема обеспечения баланса публичных и частных интересов в сфере предпринимательской деятельности // Инновационная наука. 2015. № 5. C. $99-102$.

3. По делу о проверке конституционности положений абзаца второго пункта 3 и пункта 4 статьи 44 Федерального закона «Об акционерных обществах» в связи с жалобами открытых акционерных обществ «Газпром», «Газпром нефть», «Оренбургнефть» и Акционерного коммерческого Сберегательного банка Российской Федерации (OAO): постановление Конституционного Суда РФ от 28 янв. 2010 г. № 2-П // СЗ РФ. 2010. № 6. Ст. 700.

4. Пьянкова А.Ф. Концепция баланса интересов и ее место в гражданском праве России // Вестник Пермского университета. Юридические науки. 2014. № 2(24). С. 117-130.

5. Гонгало Б.М. Идеи частного права: должное и сущее // Цивилистические записки: межвузовский сборник научных трудов. М., 2004. С. 74-75.

6. Борисенкова T.B. Соотношение частных и публичных интересов при правовом регулировании банкротства юридических лиц: дис. ... канд. юрид. наук. M., 2008. URL: https://www. dissercat.com/content/sootnoshenie-chastnykh-i-publichnykh-interesov-pri-pravovom-regulirovanii-bankrotstva-yuridi

7. Шилова Ю. Превалирование публичного интереса в банкротстве // Адвокатская газета. 2018. 23 авг. URL: https://www.advgazeta.ru/mneniya/prevalirovanie-publichnogo-interesa-vbankrotstve/

8. Попондопуло В.Ф. Некоторые проблемы совершенствования законодательства о банкротстве // Журнал предпринимательского и корпоративного права. 2016. № 1.

9. Чугунов И.Д. Правовой статус арбитражного управляющего в рамках дел о несостоятельности (банкросттве) // Наука и образование: сохраняя прошлое, создаем будущее: сборник научных статей VI международной научно-практической конференции. Пенза, 2016.

10. Душанина Е. Как усовершенствовать процедуры банкротства? // Эффективное антикризисное управление. 2011. № 5. С. 20-23.

11. Семина T.Н. Коруппциогенность норм о порядке назначения арбитражных управляющих // Инновации в науке и практике: сборник статей по материалам XV международной научно-практической конференции. Уфа, 2019. С. 45-49.

12. Законопроект о внесении изменений в Федеральный закон «О несостоятельности (банкротстве)» в части повышения гарантий независимости, добросовестности и компетентности арбитражного управляющего в ходе дела о банкротстве. URL: https:/www.eg-online. $\mathrm{ru} /$ document/law/372276/ 